\title{
STRUKTUR MIKRO DAN SIFAT MEKANIS ALUMINIUM (AI-Si) PADA PROSES PENGECORAN MENGGUNAKAN CETAKAN LOGAM, CETAKAN PASIR DAN CETAKAN CASTABLE
}

\author{
Martinus Mandala, Eddy S. Siradj dan Sofyan Djamil \\ Program Studi Teknik Mesin, Fakultas Teknik Univeritas Tarumanagara, Jakarta \\ e-mail: marthinus_mandala@yahoo.com
}

\begin{abstract}
Aluminum foundry is one of the business sectors that to much in demand by the public, ranging from small scale to large scale. Through remelting process, some small-scale aluminum casting industry, using raw materials of used aluminum as the main raw material. Some of the cast products are required to have good quality to comply with quality standards on its use. This study aims to look at the difference in quality of cast aluminum (Al-Si) using three types of mold, the metal mold, sand mold, and the mold castable by testing the mechanical properties of materials that impact and Brinell hardness testing. The method used was experimental or trial. The results obtained are the result cast using a metal mold has a hardness value of the highest of $63 \mathrm{HBN}$, with a value of impact $37 \times 10^{-2} \mathrm{~J} / \mathrm{mm}^{2}$, then the results of testing the casting using sand molds obtained hardness $54 \mathrm{HBN}$ and value impact $23 \times 10^{-2} \mathrm{~J} / \mathrm{mm}^{2}$ and the last results cast using molds castable, hardness value of $47 \mathrm{BHN}$ and the value of impact $16 \times 10^{-2} \mathrm{~J} / \mathrm{mm}^{2}$
\end{abstract}

Keywords : Aluminum,casting, furnace, cast molding, mechanical properties of materials.

\section{PENDAHULUAN}

Aluminium hasil pengecoran banyak dijumpai pada peralatan rumah tangga dan komponen otomotif misalnya velg (cast wheel), piston, blok mesin dan lain sebagainya. Aluminium hasil pembentukan diperoleh melalui tempa, rol dan ektrusi misalnya aluminium profil dan plat yang banyak digunakan dalam kontruksi. Mengolah biji logam menjadi aluminium memerlukan energi yang besar. Salah satu usaha untuk mengatasi hal ini adalah dengan melakukan daur ulang/proses pengecoran kembali. Karena keterbatasan yang ada seperti pada industri kecil (kasus pengecoran pada industri kecil) tidak semua menggunakan bahan baku, tetapi memanfaatkan aluminium sekrap ataupun rejected materials dari peleburan sebelumnya untuk dituang ulang (remelting).

Pengecoran ini untuk mengurangi pemakaian bahan baku serta agar tidak banyak material yang terbuang sia-sia, sehingga akan menghemat biaya produksi. Hasil pengecoran suatu komponen pada saat digunakan kadang mengalami beban impact sehingga peralatan tersebut harus mendapatkan jaminan terhadap kerusakan akibat impact yang dikenakan, sehingga aman dalam penggunaan atau bahkan mempunyai usia pakai (life time) lebih lama. Untuk itu tentunya perlu diketahui sifat mekanis dari material yang digunakan agar konstruksi nantinya tidak mengalami kegagalan. Pengecoran ulang adalah proses yang bertujuan untuk merubah bentuk pola yang diinginkan. Pengecoran ulang biasanya dilakukan didalam industri-industri kecil dengan menggunakan dapur sederhana dengan menggunakan tungku api atau tungku crucible dengan pembakaran menggunakan minyak tanah atau gas. Metode pengecoran yang digunakan biasanya menggunakan pengecoran tuang (grafity casting).

Terdapat berbagai ragam jenis cetakan/mold yang di gunakan dalam perindustrian, diantaranya ada cetakan pasir (sand casting), die casting, investment casting, plaster mold casting, dan masih banyak yang lainnya. Masing-masing jenis cetakan memiliki keunggulan dan kelemahan. Termasuk dari kualitas produk hasil cor. Pemilihan jenis cetakan juga di pengaruhi dari banyaknya produk yang di cetak dan biaya yang di keluarkan. Hal ini menjadi tolak ukur pemilihan jenis mold pada industri pengecoran.

Pada penelitian ini akan menganalisa struktur mikro dan sifat mekanis pada pengecoran aluminium Al-Si menggunakan 3 jenis cetakan / mold yang berbeda. Diharapkan hasil analisa nanti dapat berguna dan menjadi tambahan informasi pada teknologi pengecoran. 


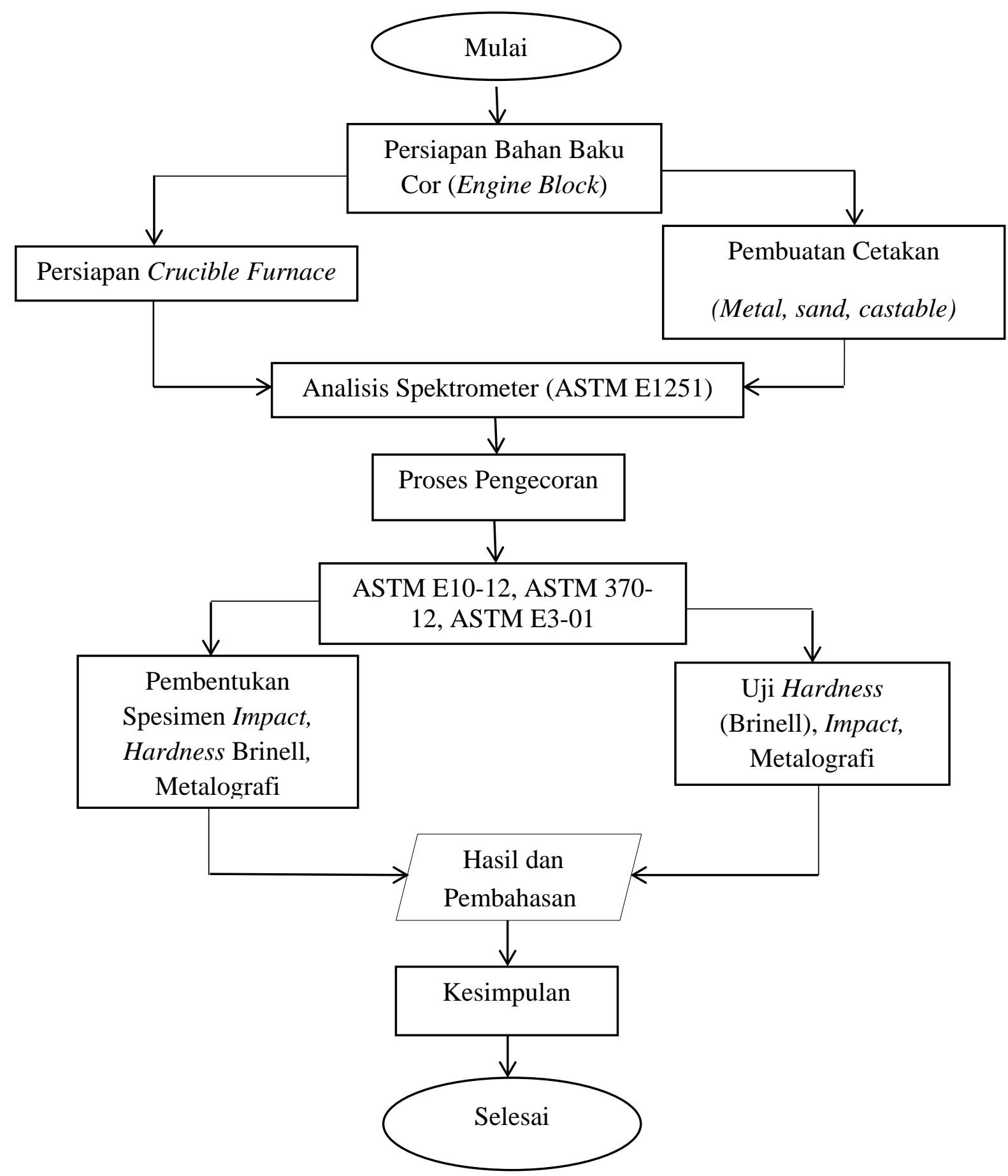

Gambar 1. Flow chart proses eksperimen yang dilakukan dalam penelitian

\section{Persiapan Bahan Baku Cor: \\ Persiapan Crucible Furnace}

Pelaksanaan penelitian ini melalui tahap peleburan. Jenis furnace yang digunakan adalah Crucible furnace. Bahan baku utama pada furnace ini menggunakan castable C-14 (semen tahan api $1400^{\circ} \mathrm{C}$ ). Tujuan pemilihan castable C-14 adalah agar tidak terjadi over heating pada saat proses peleburan, sama halnya dengan dimensi dinding furnace seperti pada gambar ilustrasi. Untuk ilustrasi dan dimensi crucible furnace ddapat dilihat pada Gambar 3. 


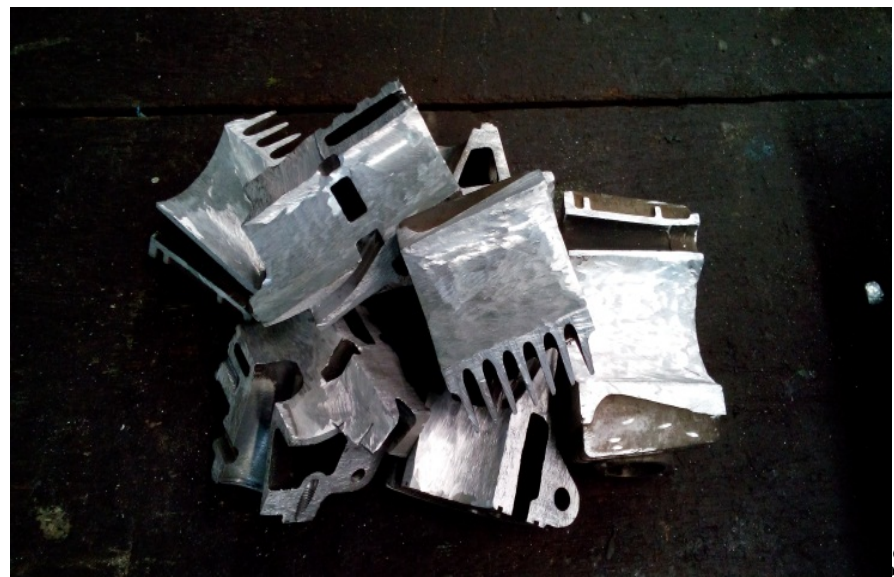

Skala $1: 4$

Gambar 2. Engine block yang akan di lebur, dan telah dipotong-potong agar dapat dimasukan ke dalam crucible.
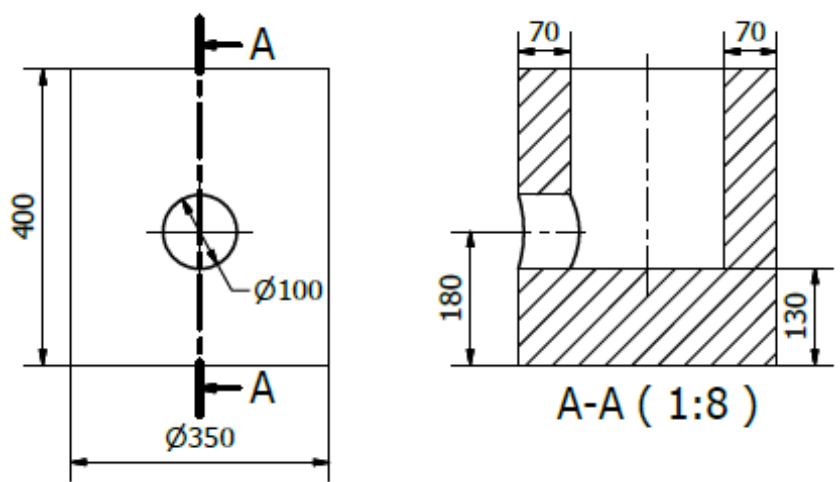

A-A $(1: 8)$

Gambar 3. Ilustrasi bentuk dan dimensi crucible yang di gunakan pada penelitian.

\section{Proses Pembuatan Cetakan}

Cetakan Logam
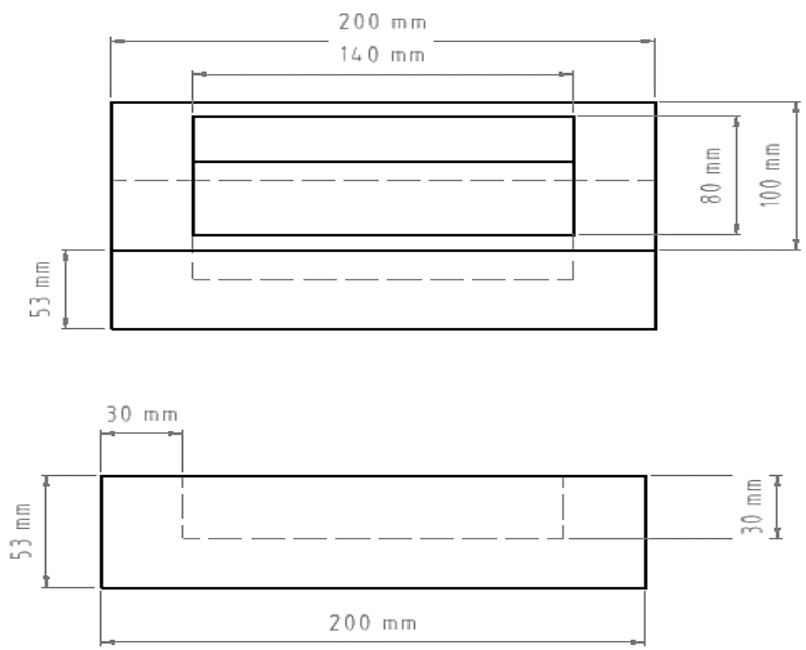

Gambar 4. Ilustrasi bentuk dan dimensi cetakan logam yang digunakan pada proses penelitian.

Cetakan logam yang digunakan pada penelitian ini menggunakan material ST-41. Tujuan pemilihan material ST-41 untuk bahan cetakan logam karena perbedaan melting point yang jauh dengan bahan yang akan dicor. 


\section{Cetakan Pasir}
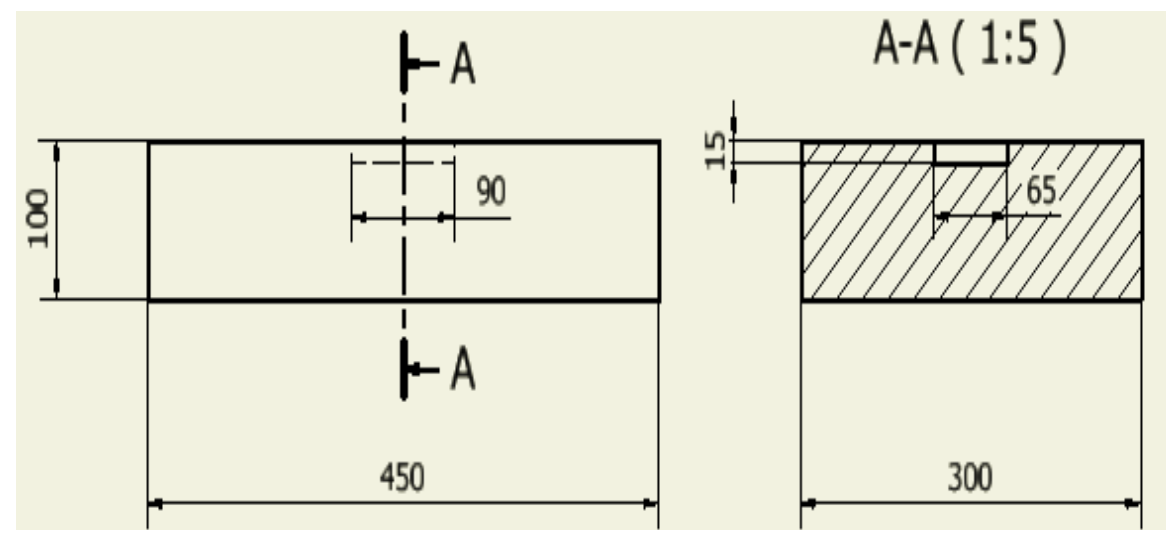

Gambar 5. Ilustrasi bentuk dan dimensi cetakan pasir yang digunakan pada proses penelitian.

Pasir yang digunakan untuk pembuatan cetakan pada penelitian menggunakan pasir cetak. Pola di bentuk menggunakan potongan kayu dengan dimensi yang telah disesuaikan untuk pembuatan spesimen uji kekerasan (Brinell), Impact dan metalografi.

\section{Cetakan Castable}
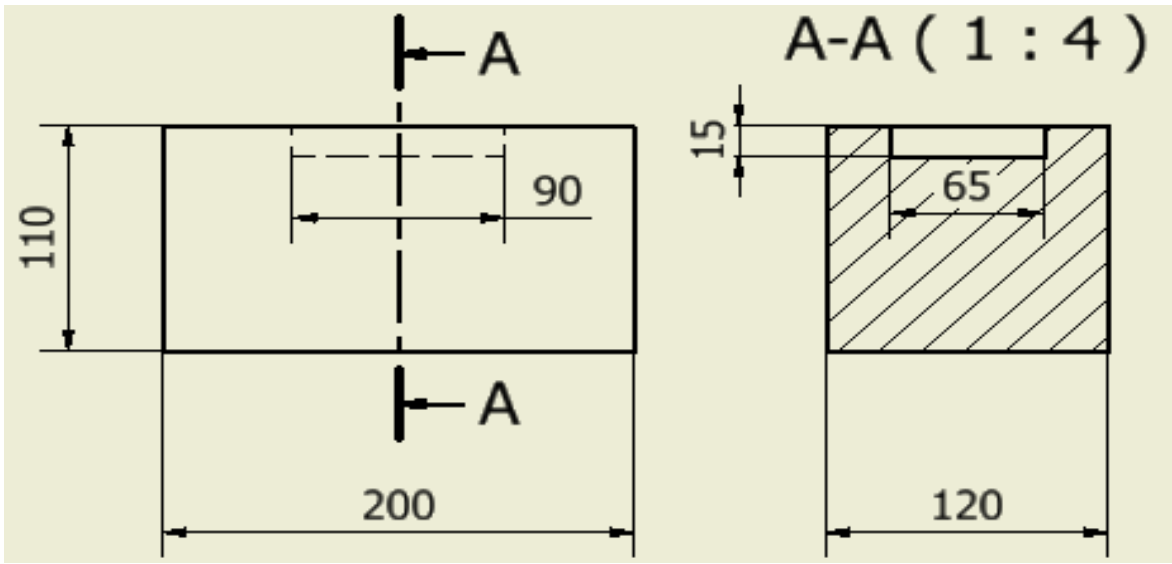

Gambar 6. Ilustrasi bentuk dan dimensi cetakan castable yang digunakan pada proses penelitian.

Castable yang digunakan untuk pembuatan cetakan adalah jenis C-14. Jenis ini mampu menahan panas hingga $1400^{\circ} \mathrm{C}$.

\section{Analisis Spektrometer}

Sebelum melakukan proses peleburan, diperlukan analisis komposisi kimia dari bahan baku (engine block) yang hendak dilebur menggunakan alat yang di sebut Optical Emission Spectrometer. Setalah komposisi kimia diketahui, maka dapat diketahui kategori penomoran material tersebut. Perubahan fasa yang terjadi dan titik lebur juga dapat dilihat melalui diagram fasa. Analisis komposisi kimia dilakukan di Laboratorium Uji Departemen Teknik Metalurgi \& Material - Universitas Indonesia.

\section{Pembentukan Spesimen dan Pengujian}

Proses pembentukan spesimen dilakukan menggunakan mesin milling CNC di Laboratorium CNC kampus Universitas Tarumanagara. Dimensi spesimen uji Impact sesuai standard ASTM 37012, dan dimensi uji kekerasan metode Brinell serta metalografi dapat dilihat pada Gambar 8 dan Gambar 9. 


\section{Proses Pengecoran}

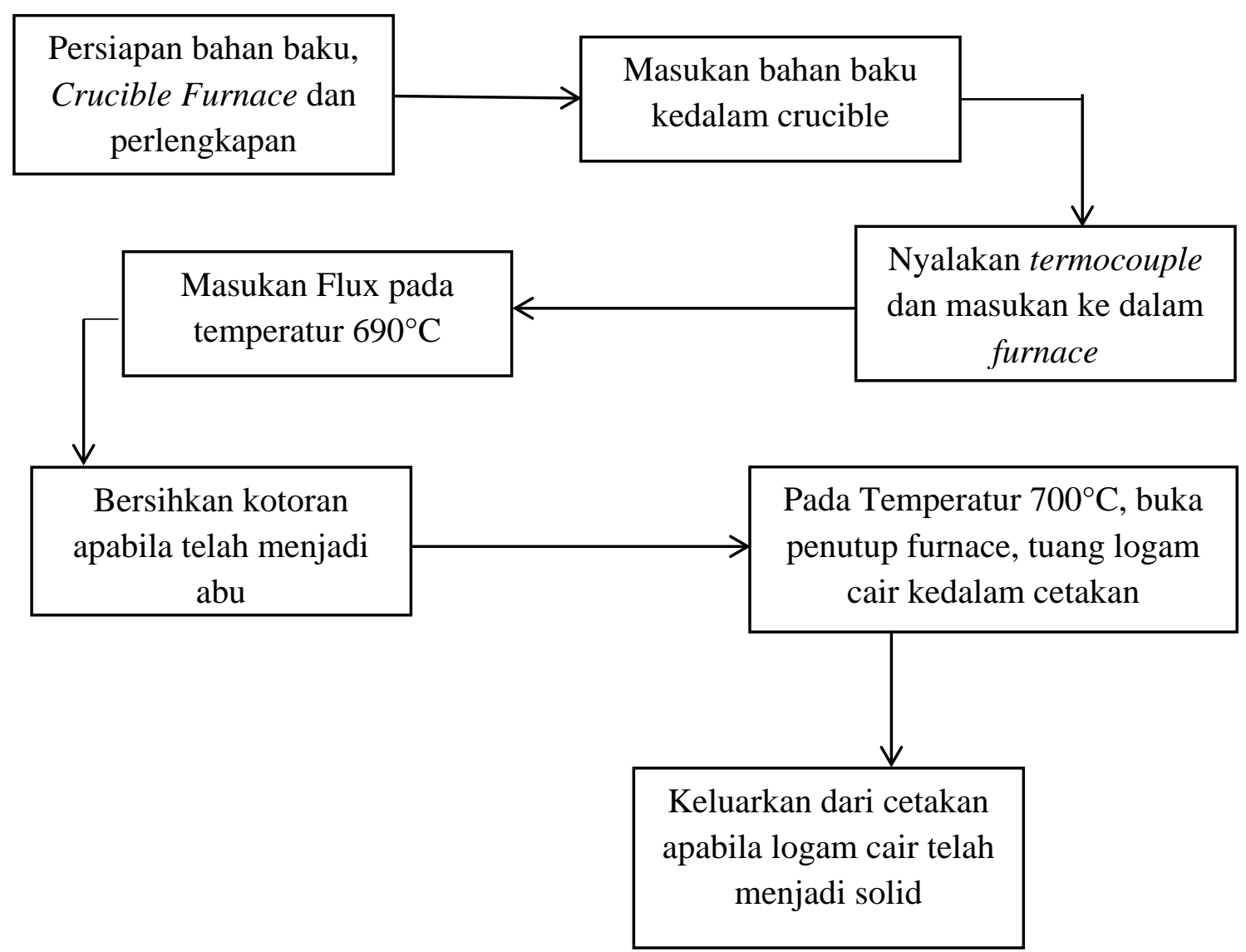

Gambar 7. Tahapan proses pengecoran menggunakan crucible furnace

\section{a. Uji Impact Charphy}
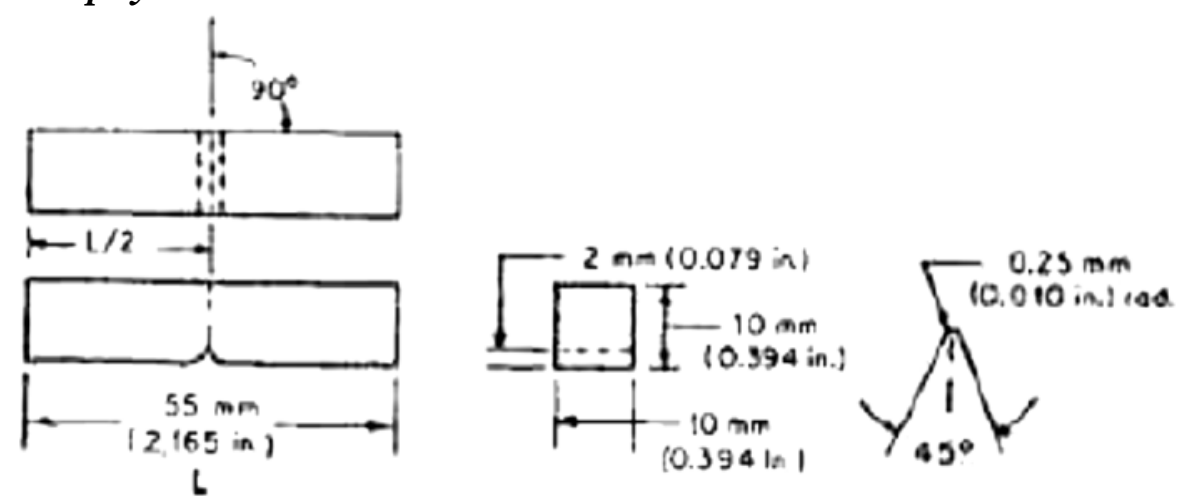

Gambar 8. Ilustrasi dimensi spesimen uji Impact sesuai standard ASTM 370-12

Gambar 8 merupakan ilustrasi dimensi spesimen uji impact yang dibuat dalam penelitian ini. Pengujian Impact dilakukan dengan metode charpy. Dari pengujian akan didata sudut posisi akhir pendulum $(\cos \beta)$ kemudian dihitung nilai Impact dengan menggunakan rumus di bawah ini : Mencari usaha yang diperlukan untuk mematahkan spesimen (J) :

$$
\mathrm{W}=\mathrm{G}-\gamma(\operatorname{Cos} \beta-\operatorname{Cos} \alpha) \times g
$$

\section{Dengan :}

W : usaha yang diperlukan untuk mematahkan spesimen (J) 
G : berat golan (pendulum) $(\mathrm{kg})$

$\gamma \quad$ : jarak lengan pengayun (m)

g : gaya gravitasi $\left(\mathrm{m} / \mathrm{s}^{2}\right)$

$\cos \alpha$ : sudut posisi awal pendulum

$\cos \beta$ : sudut posisi akhir pendulum

Berikut spesifikasi alat uji Impact tipe charpy yang digunakan :

$\begin{array}{ll}\mathrm{G} & : 26,12 \mathrm{~kg} \\ \gamma & : 0,75 \mathrm{~m} \\ \cos \alpha & : 144^{\circ}\end{array}$

Nilai Impact :

$$
\mathrm{K}=\left(\frac{W}{A}\right)
$$

Dengan :

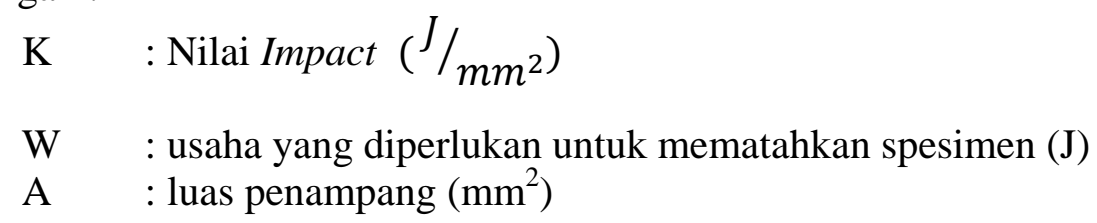

\section{b. Uji kekerasan Metode Brinell}
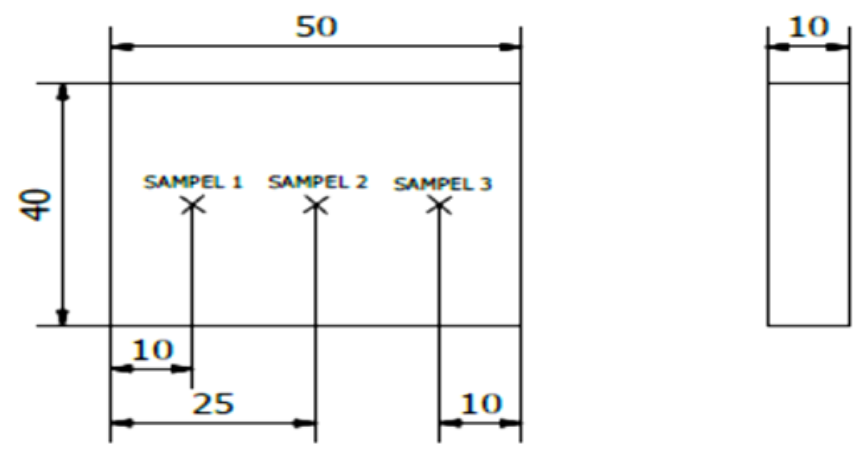

Gambar 9 Ilustrasi dimensi spesimen uji kekerasan Brinell dan posisi titik pengambilan sampel.

\section{c. Spesimen Metalografi}
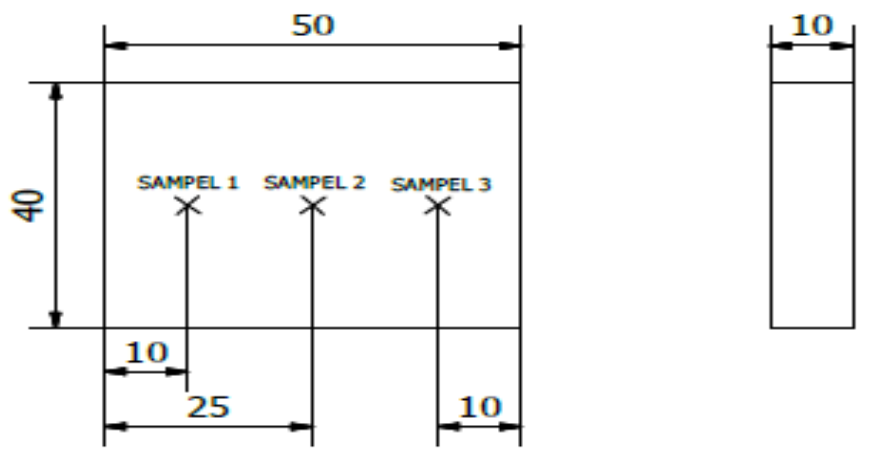

Gambar 10. Ilustrasi dimensi spesimen metalografi dan posisi titik pengambilan sampel.

Setelah pembentukan spesimen sesuai dimensi pada gambar 3.10, dilakukan proses (grinding) menggunakan amplas 500,1000, dan 1200 kemudian dipoles dengan autosol menggunakan kain bersih dan halus. Setelah itu dilakukan etching menggunakan cairan 0,5\% Hydroflourid Acid sesuai dengan standard ASTM E3 - 01. 


\section{HASIL DAN PEMBAHASAN}

\section{Komposisi Kimia Bahan Baku (engine block)}

Tabel 1 Hasil uji komposisi kimia dari baha baku engine block (\% / weight) yang merupakan hasil rata-rata dari pengambilan 3 titik yang berbeda menggunakan alat Optical Emission Spectrometer

\begin{tabular}{cccccc}
\hline Si (\%) & Fe (\%) & Cu (\%) & Mn (\%) & Mg (\%) & Zn (\%) \\
\hline 5,47 & 0,613 & 1,38 & 0,168 & 0,360 & 0,368 \\
\hline Cr (\%) & Ni (\%) & Ti (\%) & Pb (\%) & Sn (\%) & Al (\%) \\
\hline 0,039 & 0,124 & 0,035 & 0,045 & 0,060 & Bal.
\end{tabular}

(Sumber : pengujian di laboratorium Uji Departemen Teknik Metalurgi \& Material Universitas Indonesia)

Tabel 1 menunjukan bahwa bahan baku cor yang digunakan (engine block) merupakan aluminium paduan silikon (Al-Si) 5,5\%. Diagram fasa yang digunakan adalah diagram fasa Al-Si seperti pada Gambar 11 di bawah ini.

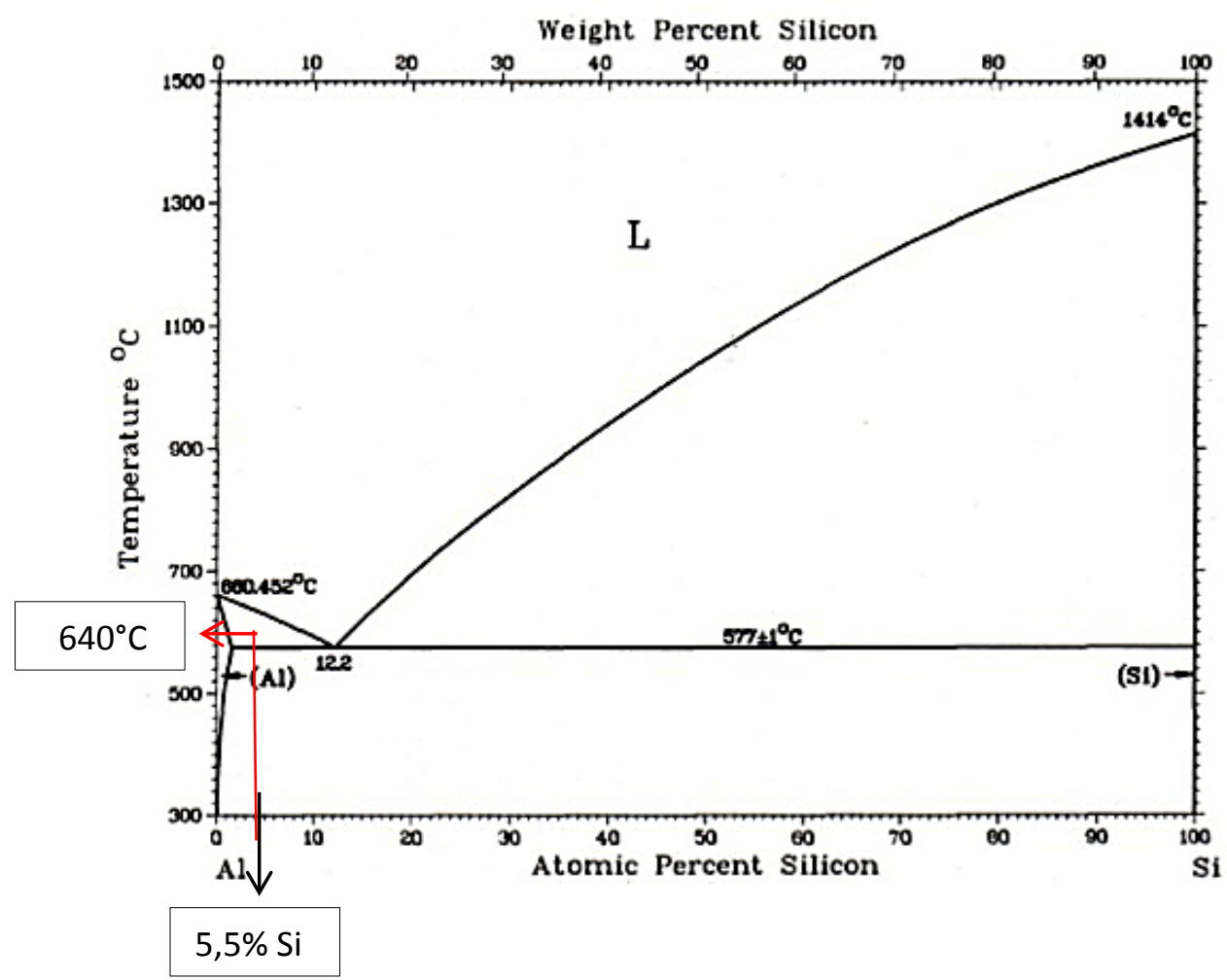

Gambar 11. Pembacaan temperatur pada diagram fasa Al-Si, menunjukan fasa cair bahan cor (aluminium-silikon 5,5\%) yang digunakan dalam penelitian berada pada temperatur $640^{\circ} \mathrm{C}$.

Informasi dari diagram fasa yang menunjukan fasa liquid terjadi pada material cor jika dipanaskan/dilebur yaitu pada temperatur $640^{\circ} \mathrm{C}$. sehingga pada proses penelitian tepatnya pada tahap peleburan dapat ditentukan batas temperatur peleburan untuk mencapai temperatur penuangan yang tepat atau menghindari terjadinya perubahan fasa pada saat penuangan yang memungkinkan hasil cor akan menjadi gagal, cacat cor atau solidifikasi tidak sempurna.

Pada diagram juga menjelaskan bahwa paduan silikon 5,5\% terdapat 3 fasa sesuai dengan kenaikan temperatur jika dipanaskan. Fasa solid berada pada temperatur $<577^{\circ} \mathrm{C}$, dan akan 
mengalami fasa lumpur pada range temperatur $577^{\circ} \mathrm{C} \mathrm{s} / \mathrm{d} 640^{\circ} \mathrm{C}$, kemudian akan berubah menjadi fasa cair (liquid) setelah temperatur $>640^{\circ} \mathrm{C}$.

\section{Metalografi}

Proses pengamatan struktur mikro dilakukan dengan pembesaran 500× dan prosedur pengujian berdasarkan standard ASTM E3-01, Berikut adalah gambar struktur dari hasil cor masing-masing jenis cetakan.

a. Cetakan Castable

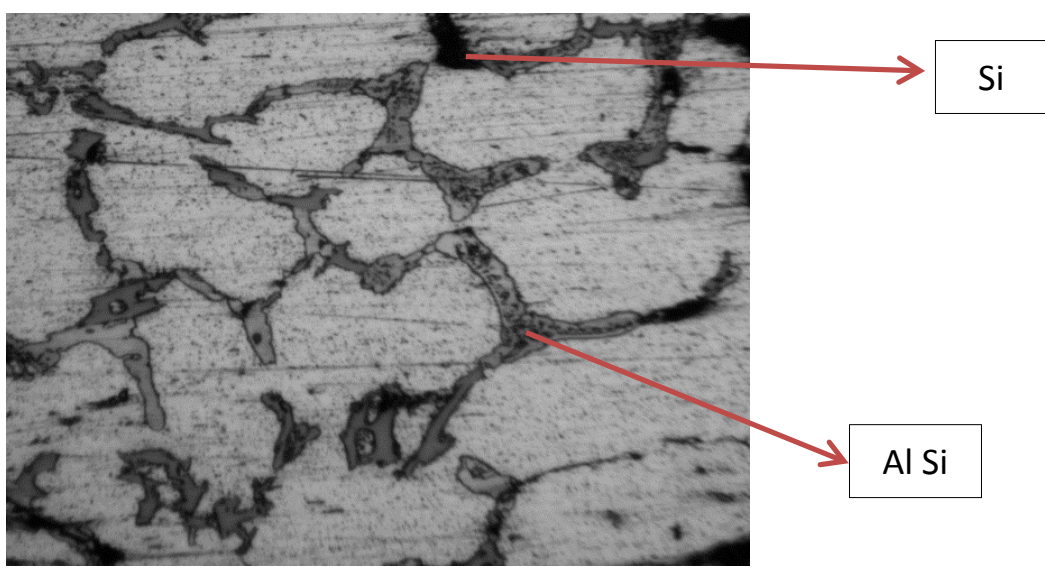

Gambar 12. Struktur mikro Al-Si 5,5 \% hasil cor cetakan castable pembesaran 250×, menggunakan etsha $0,5 \%$ Hydroflourid Acid

b. Cetakan Pasir

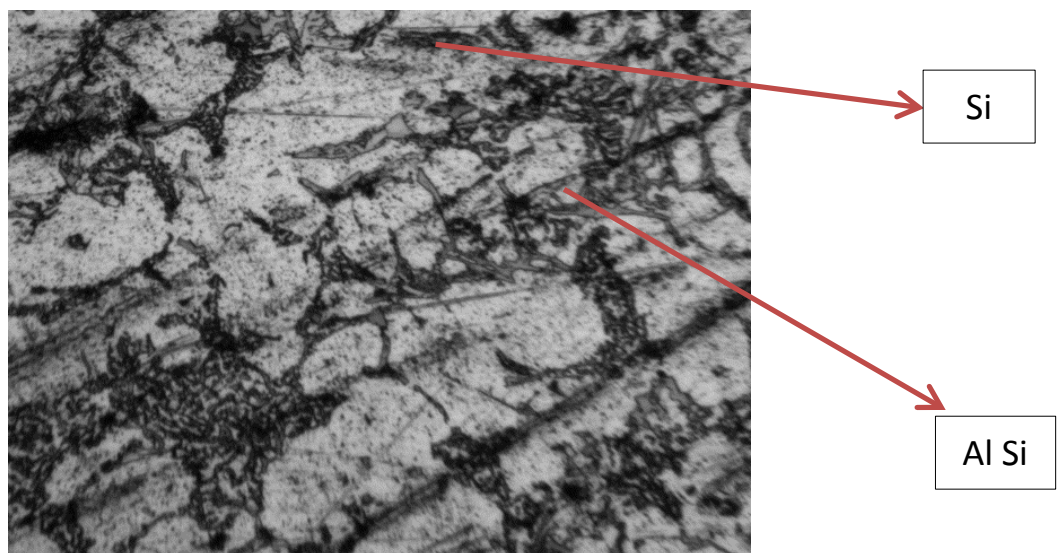

Gambar 13. Struktur mikro Al-Si 5,5 \% hasil cor cetakan pasir, pembesaran 250×, menggunakan etsha $0,5 \%$ Hydroflourid Acid

c. Cetakan Logam

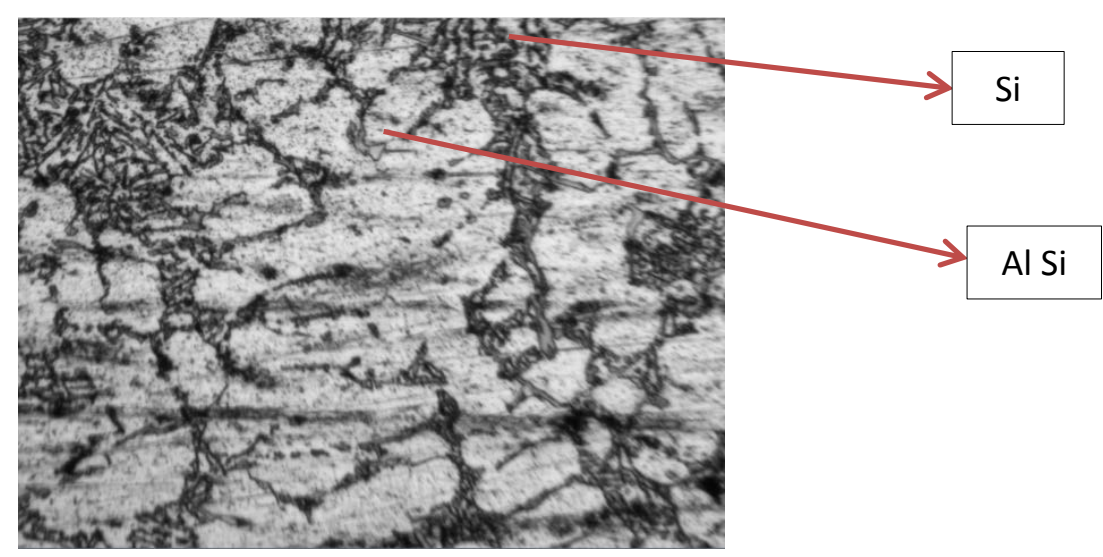


Gambar 14. Struktur mikro Al-Si 5,5 \% hasil cor cetakan logam pembesaran 250×, menggunakan etsha $0,5 \%$ Hydroflourid Acid

Berdasarkan pengamatan struktur mkro yang telah dilakukan, terdapat perbedaan antara struktur mikro hasil cor menggunakan cetakan logam, cetakan pasir, dan cetakan castable, diantaranya :

> Struktur mikro hasil cor cetakan castable, struktur dendrite terlihat paling besar jika dibandingkan dengan struktur dendrite pada hasil cor menggunakan cetakan pasir dan logam.

> Struktur mikro hasil cor cetakan pasir terlihat struktur dendrite lebih kecil dibandingkan hasil cetakan castable, dengan demikian, proses solidifikasi lebih cepat dibandingkan cetakan castable.

> Struktur mikro hasil cor cetakan logam terlihat struktur dendrite lebih kecil dan persebaran butir lebih merata dibandingkan hasil cetakan pasir dan castable, dengan demikian proses solidifikasi paling cepat terjadi pada cetakan logam.

\section{Hasil Uji Kekerasan (Brinell)}

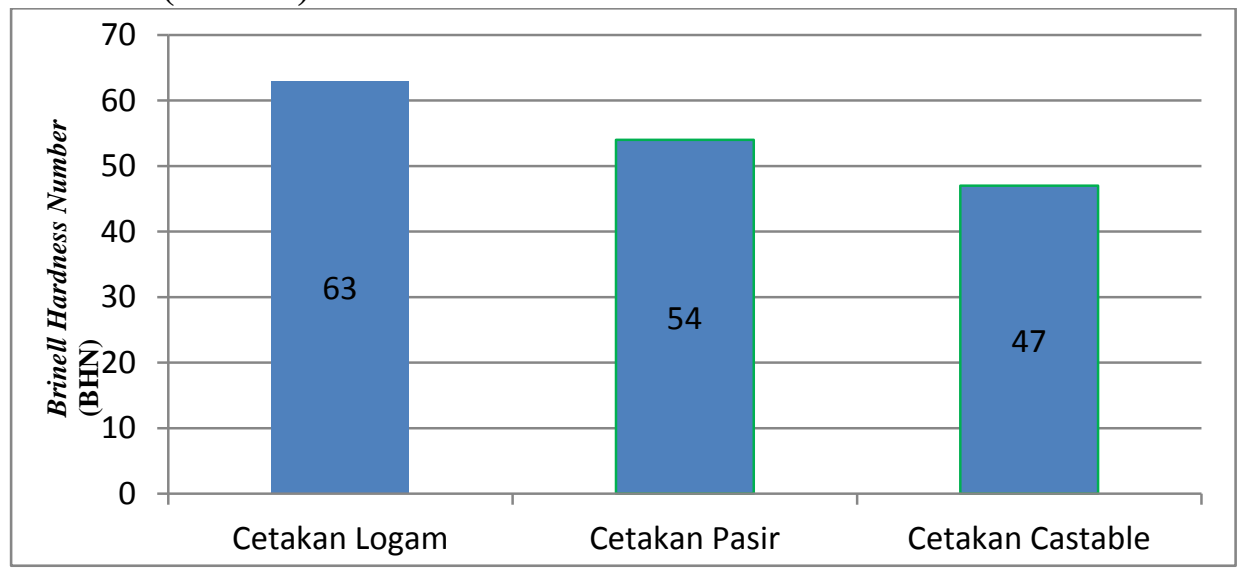

Gambar 15. Perbedaan nilai kekerasan Brinell pada hasil cor menggunakan cetakan logam, cetakan pasir, dan cetakan castable

Pada hasil cetakan logam, nilai kekerasan 63 BHN, lebih tinggi dibandingkan nilai kekerasan dari hasil cor menggunakan cetakan pasir yaitu 54 BHN dan cetakan castable yang hanya 47 BHN. Perbedaan ini berhubungan dengan besar butir, hasil cor yang mengggunakan cetakan logam, yang memiliki laju solidifikasi paling cepat diantara ketiga cetakan, butir paling kecil dan persebarannya merata akan memiliki nilai kekerasan yang tinggi, sedangkan butir yang tumbuh tidak merata dan besar akan meiliki nilai kekerasan yang rendah.

\section{Hasil Uji Impact Charpy}

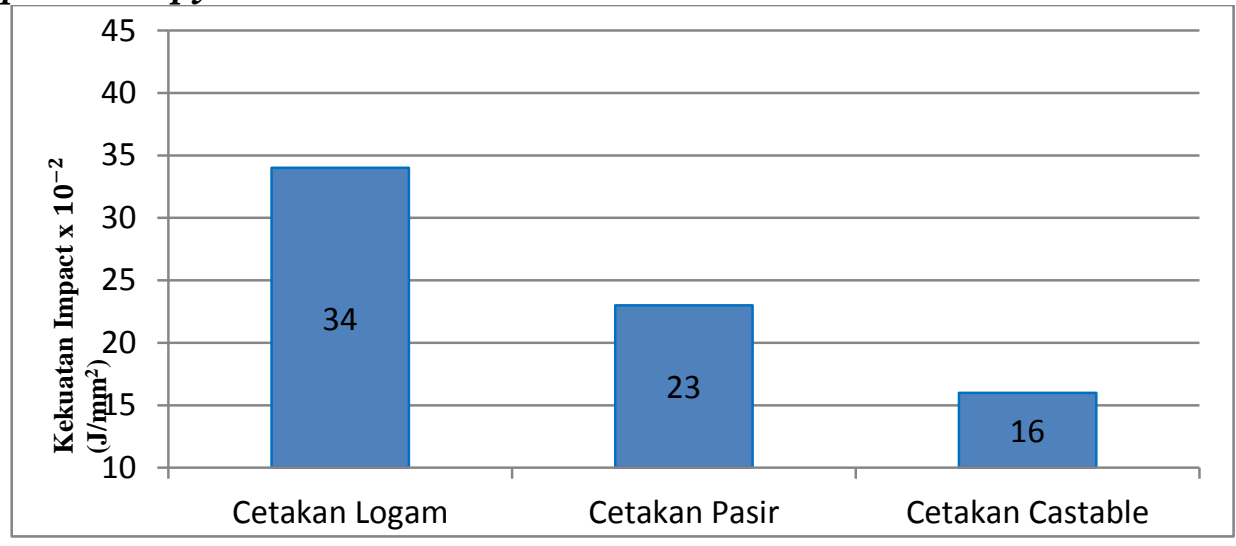


Gambar 16. Perbedaan nilai Impact pada hasil cor menggunakan cetakan logam, cetakan pasir, dan cetakan castable

Pada hasil cetakan logam, nilai Impact $34 \times 10^{-2} \mathrm{~J} / \mathrm{mm}^{2}$, lebih tinggi dibandingkan nilai Impact dari hasil cor menggunakan cetakan pasir yaitu $23 \times 10^{-2} \mathrm{~J} / \mathrm{mm}^{2}$ dan cetakan castable yang hanya $16 \times 10^{-2} \mathrm{~J} / \mathrm{mm}^{2}$

Hasil cor cetakan castable memiliki sifat keuletan paling tinggi diantara hasil cor cetakan pasir dan logam. Seperti dengan nilai kekerasan, nilai impact suatu material juga dipengaruhi oleh besar butir dan persebaran butirnya. Hasil cor yang memiliki nilai kekerasan yang tinggi akan bersifat getas, dan sebaliknya, material yang memiliki nilai kekerasan rendah, maka sifat material tersebut ulet.

Hubungan antara nilai kekerasan dan nilai impact yang diperoleh dari pengujian hasil cor dalam penelitian ini dapat dilihat berupa grafik di bawah ini:

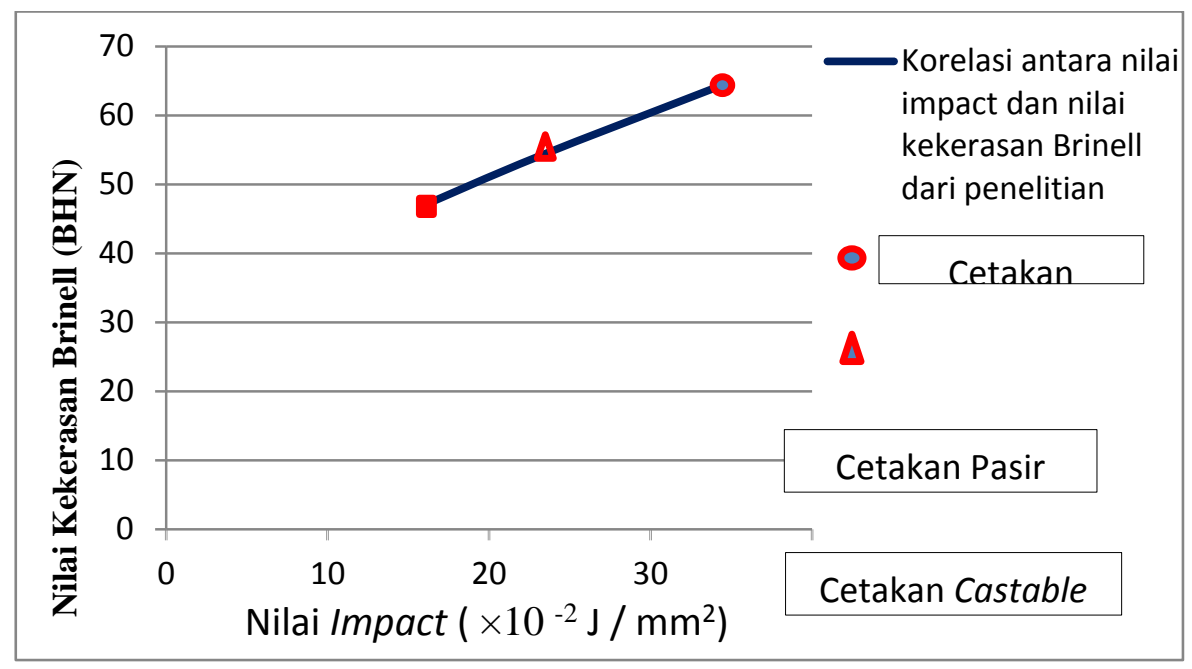

Gambar 17. Korelasi antara nilai Impact dan nilai kekerasan Brinell dari hasil penelitian menjelaskan bahwa semakin keras bahan cor, maka semakin besar juga nilai impact (bersifat getas), dan jika nilai kekerasan kecil, maka bersifat ulet.

\section{KESIMPULAN}

1. Proses pengecoran Al-Si 5,5\%, mengggunakan cetakan logam menghasilkan benda cor yang memiliki nilai kekerasan $63 \mathrm{BHN}$, cetakan pasir 54 BHN dan castable dengan nilai kekerasan dan 47 BHN.

2. Nilai impact benda cor hasil pengecoran menggunakan cetakan logam bernilai $34 \times 10^{-2} \mathrm{~J} /$ $\mathrm{mm}^{2}$, cetakan pasir $23 \times 10^{-2} \mathrm{~J} / \mathrm{mm}^{2}$, dan cetakan castable $16 \times 10^{-2} \mathrm{~J} / \mathrm{mm}^{2}$. Nilai impact hasil cetakan logam bernilai tinggi, yang berarti benda cor tersebut bersifat getas, sedangkan nilai impact kecil, benda cor bersifat ulet.

3. Struktur mikro hasil cor cetakan castable, struktur dendrite terlihat paling besar jika dibandingkan dengan struktur dendrite pada hasil cor menggunakan cetakan pasir dan logam. Pada struktur mikro hasil cor cetakan pasir terlihat struktur dendrite lebih kecil dibandingkan hasil cetakan castable, dengan demikian, proses solidifikasi lebih cepat dibandingkan cetakan castable, dan Struktur mikro hasil cor cetakan logam terlihat struktur dendrite lebih kecil dan persebaran butir lebih merata dibandingkan hasil cetakan pasir dan castable, dengan demikian proses solidifikasi paling cepat terjadi pada cetakan logam.

\section{DAFTAR PUSTAKA}


[1]. Diah Kusumah, Hubungan Jenis Cetakan Terhadap Kaulitas Cor Aluminium,UNSRI, (Journal - SNNTM XI, UGM, Yogyakarta). 2012

[2]. F. A. Lewis, “ Alumunium Alloy Casting And Foundry “, Jhon Winley and Sons, New York, 1976

[3]. Jurnal Standard Test Methods and Definitions for Mechanical Testing of Steel Products, Universitas Teknologi Malaysia

[4]. American Society for Testing and Material, Manual on Impact Testing, ASTM STP, Vol 465, Philadelphia, PA, 1969.

[5]. Mott, Robert L. Machine Elements in Mechanical Design $4^{\text {th }}$ edition University of Dayton, 2004

[6]. J. Campbell, Castings Practice: The Ten Rules of Castings ,Oxford, United Kingdom: Butterworth Heinemann, 2005

[7]. Randi GPP, Kajian Eksperimental Pengaruh Perubahan Ukuran Cetakan Pasir Terhadap Perubahan Struktur Mikro dan Kekerasan Produk Cor Aluminium, Jurusan Teknik Mesin FT UNSRI, 2011

[8]. Samsudi Raharjo, Analisa Pengaruh Pengecoran Ulang Terhadap Sifat Mekanik ADC12, Jurnal, Seminar Nasional Sains, (Universitas Muhamadiyah Semarang). 2011

[9]. ASM Metal Handbook 8th Vol 7, Atlas Microstructure Of Industrial Alloys : American Society For Metal 